\title{
Young drivers' perception of adult and child pedestrians in potential street-crossing situations
}

\author{
Abele, Liva; Haustein, Sonja; Møller, Mette
}

Published in:

Accident Analysis and Prevention

Link to article, DOI:

10.1016/j.aap.2018.03.027

Publication date:

2018

Document Version

Peer reviewed version

Link back to DTU Orbit

Citation (APA):

Abele, L., Haustein, S., \& Møller, M. (2018). Young drivers' perception of adult and child pedestrians in potential street-crossing situations. Accident Analysis and Prevention, 118, 263-268.

https://doi.org/10.1016/j.aap.2018.03.027

\section{General rights}

Copyright and moral rights for the publications made accessible in the public portal are retained by the authors and/or other copyright owners and it is a condition of accessing publications that users recognise and abide by the legal requirements associated with these rights.

- Users may download and print one copy of any publication from the public portal for the purpose of private study or research.

- You may not further distribute the material or use it for any profit-making activity or commercial gain

- You may freely distribute the URL identifying the publication in the public portal

If you believe that this document breaches copyright please contact us providing details, and we will remove access to the work immediately and investigate your claim 


\title{
Young drivers' perception of adult and child pedestrians in potential street-crossing situations
}

\author{
Līva Ābele* \\ DTU Management, Diplomvej, Building 372, DK-2800 Kgs. Lyngby, Denmark, livab@dtu.dk \\ Sonja Haustein \\ DTU Management, Diplomvej, Building 371, DK-2800 Kgs. Lyngby, Denmark, sonh@dtu.dk \\ Mette Møller \\ DTU Management, Diplomvej, Building 372, DK-2800 Kgs. Lyngby, Denmark, mette@dtu.dk \\ *corresponding author
}

\section{Abstract}

Despite overall improvements in road traffic safety, pedestrian accidents continue to be a serious public health problem. Due to lack of experience, limited cognitive and motoric skills, and smaller size, children have a higher injury risk as pedestrians than adults. To what extent drivers adjust their driving behaviour to children's higher vulnerability is largely unknown. To determine whether young male drivers' behaviour and scanning pattern differs when approaching a child and an adult pedestrian in a potential street-crossing situation, sixty-five young (18-24) male drivers' speed, lateral position and eye movements were recorded in a driving simulator. Results showed that fewer drivers responded by slowing down and that drivers had a higher driving speed when approaching a child pedestrian, although the time of the first fixation on both types of pedestrians was the same. However, drivers drove farther away from a child than an adult pedestrian. Additionally, fewer drivers who did not slow down fixated on the speedometer while approaching the child pedestrian. The results show that young drivers behave differently when approaching a child and an adult pedestrian, though not in a way that appropriately accounts for the limitations of a child pedestrian. A better understanding of how drivers respond to different types of pedestrians and why could contribute to the development of pedestrian detection and emergency braking systems.

Keywords: Young male drivers, Pedestrians, Driving simulator, Eye movements 


\section{Introduction}

Pedestrian fatalities make up an essential proportion of the overall number of road traffic deaths and thus require attention. Internationally, the number of fatalities has substantially decreased over the past decade, but less among pedestrians compared to drivers. From 2000 to 2013, fatalities among drivers decreased by $54 \%$ while pedestrian fatalities decreased by 36\% (OECD/IFT, 2015). Moreover, indications of an increasing number of fatalities among vulnerable road users exist (OECD/IFT, 2015), and pedestrian accident injuries continue to be a serious road safety problem.

In 2015 more than one-fifth (21\%) of children up to 14 years of age killed in traffic crashes were pedestrians (National Center for Statistics and Analysis, 2017). Therefore, research to support the development of targeted interventions aimed at young pedestrians is required.

Previous studies have aimed at identifying factors of child pedestrian risk. For instance, in relation to the most common road traffic accident situation among children, unsafe street crossing, studies show that advanced perceptual and cognitive skills are needed (Schwebel et al., 2012). Research shows that young children have lower hazard perception skills than adults (Meyer et al., 2014) and are more prone to impulsive actions in traffic (Briem and Bengtsson, 2000). Children have difficulty assessing a car's approaching speed and therefore interpret distance between themselves and a car as greater than it actually is (Connelly et al., 1998). Further, even if children may choose the same gap size for crossing the street, their risk of accident involvement is increased as they delay the start of the crossing, thereby reducing the available time to cross the street safely (e.g. Pitcairn and Edlmann, 2000). As can be seen, previous studies have successfully identified cognitive immaturity, lack of perceptual and motor abilities, and inexperience as factors contributing to the risk of accident involvement among child pedestrians. However, with regard to child pedestrian accidents, research has mainly focussed on the behaviour and skills of the child (Hamed, 2001; Jager et al., 2015; Schwebel et al., 2012; Zito et al., 2015), whereas the role of the driver - including driver errors and flaws in perceptual and motor processes - remains rather unexplored (Poschadel, 2006; Stewart et al., 1993). However, because of children's limited cognitive and motoric skills, knowledge of driver behaviour in relation to child 
pedestrians and driver awareness of the need for increased safety margins in relation to child pedestrians is highly relevant.

Additional emphasis has been placed on examining the role of the built environment and other infrastructural factors (Bennet and Yiannakoulias, 2015; Cloutier et al., 2017; Rothman, 2014) as they have been found related to accident risk: the risk of a pedestrian accident is higher, for example, in urban than in rural areas (National Center for Statistics and Analysis, 2017). Moreover, 72\% of pedestrian fatalities occur in non-intersection locations, where there are no traffic controls (National Center for Statistics and Analysis, 2017); roads are wide, encouraging higher speeds; and parking is permitted, preventing drivers from detecting children from behind parked vehicles (Schieber and Vegega, 2002). Even though young children more often than older children and adults become victims in accidents with parked cars, as they are then not visible to the driver and cannot see the approaching vehicle themselves, situations with visible children crossing the street are among the most frequent accident situations among children 14 years of age or younger (Poschadel, 2006). In these situations, the driver clearly has the opportunity to detect the child and to react by speed adjustment. Why, in case of accidents, this did not happen often remains unclear.

One potential reason is that the distance to a pedestrian is mainly estimated based on reference size, so drivers often falsely perceive that children are farther away than they actually are, overestimating the time-to-collision (Stewart et al., 1993). This factor is less relevant where other cars are present that can serve as a reference to the size of the pedestrian. Therefore, there is a necessity to understand driving behaviour in situations of approaching pedestrians where other vehicles are present (and are not hiding the pedestrian). While studies show that drivers make inadequate speed and lateral position adjustments when passing child pedestrian on the roadside (Thompson et al., 1985), it remains unclear if this is a problem particularly related to child pedestrians or of similar relevance for adult pedestrians.

Driver characteristics also contribute to child pedestrian injuries (Stewart et al., 1993; Thompson et al., 1985). Specifically, young male drivers are more likely to be involved in accidents with child pedestrians (Thompson et al., 2003), which may be related to their lower hazard perception skills (e.g. Borowsky et al., 2010) and higher risk acceptance (e.g. Clarke et al., 2005; Williams, 2003). 
Due to limited cognitive skills, children are more unpredictable in road-crossing situations but, so far, it is not clear whether young drivers are considering any differences when encountering child or adult pedestrians on the road. Based on the above, this study aims to determine whether driving behaviour and scanning patterns among young male drivers are different when approaching a child versus an adult pedestrian.

When deciding on methods and measures to use in research on drivers' behaviour in pedestrian crossing situations, one must balance the goal of testing drivers in realistic and controllable traffic with the ability to keep them safe. The driving simulator meets these conditions. Even though behavioural data can give an indication of how pedestrians are perceived and responded to, eye movement data provide a more profound insight into the detection of pedestrians. The visual skills required for safe driving are gained with practice (e.g. Borowsky et al., 2010; Chapman and Underwood, 1998; Konstantopoulos et al., 2010; Underwood et al., 2002). Experienced drivers detect hazards earlier (e.g. Deery, 1999), while novice drivers have longer (e.g. Chapman and Underwood, 1998) and fewer (Pradhan et al., 2007) fixations on hazards, representing a slower processing speed.

Recently, cars have become increasingly well-equipped with technical systems to warn the driver of hazards and automated braking systems to prevent crashes with pedestrians (Coelingh et al., 2010; Rosén et al., 2010). However, one of the major challenges of these systems is to balance their performance against the possibility of unwanted system activation (Lubbe and Davidsson, 2015). Therefore, they still need to be optimised to provide drivers with feelings of comfort and involvement in the driving activity. Gaining more insight into how drivers respond and scan for pedestrians, not only of varying physical aspects but also of different predictability, could help in the development of more sensitive and smoother performance of these technical systems.

To increase the understanding of the role of drivers in situations with child pedestrians, this study compared young male drivers' detection of child and adult pedestrians with and without parked cars partly obstructing the view of the driver. We simulated potential pedestrian crossing situations to examine the driving performance and eye movements of drivers. We expected that drivers would adjust 
their driving performance more when a child than when an adult pedestrian was present (i.e. by lowering driving speed and/or driving farther away from the pedestrian).

\section{Method}

\subsection{Participants}

Sixty-five male drivers between 18 and 24 years of age $(M=21.91, S D=1.48)$ participated in the experiment. All participants had self-reported normal or corrected-to-normal vision and had valid drivers' licences for between 0.5 to 6 years $(\mathrm{M}=3.82$, $\mathrm{SD}=1.35)$. They were recruited among university students, and each received a gift card (worth 30 Euros) or credit points for participation.

\subsection{Apparatus}

A fixed-based medium-fidelity driving simulator equipped with the necessary vehicle control systems and 3D sound system (5.1-channel) was used to conduct the experiment. On three plasma displays (size: 42”; the front screen resolution: 1920 x $1080 \mathrm{dpi}$, the side screens' resolution: 1360 x $768 \mathrm{dpi}, 150^{\circ}$ horizontal and $40^{\circ}$ vertical perspective) scenarios were presented at a rate of 60 frames per second. Speedometer, rear- and side-view mirror information was visible on the centre and side screens. The real-time simulation and scenarios were developed with SCANeR Studio (OKTAL) software.

Eye movements were recorded with Tobii Pro Glasses 2 eye tracker (a sampling frequency of $50 \mathrm{~Hz}$ ). Tobii I-VT Fixation Filter (minimum fixation duration $=60 \mathrm{~ms}$, velocity threshold $=30 \% \mathrm{~s}$, and $\mathrm{max}$ angle between fixations $=0.5^{\circ}$ ) fixation classification algorithm was used (Tobii Technology, 2012) .

\subsection{Scenarios}

The driving environment was designed to match the typical urban setting of a Danish urban street with speed limit of $50 \mathrm{hm} / \mathrm{h}$ and contained buildings, parked cars and street furniture. The drive was three kilometres long and included six pedestrian-related hazard situations. The participants encountered each situation in two conditions, hidden and visible, and with two types of pedestrians, adult and child, 24 situations altogether.

The present study analysed each participant's driving behaviour and eye movements in one of the six hazard situations, both with an adult pedestrian and with a child pedestrian in the visible and hidden 
condition. The selected situation was a potential street-crossing situation and was chosen as it is the most common accident situation among child pedestrians in Denmark. In the situation, a pedestrian (adult or child, see Figure 1) was standing on the pavement on the left side of the street. Children were dressed in clothes in bright colours, while adults were wearing grey clothes to make differences of pedestrian types more noticeable and realistic.

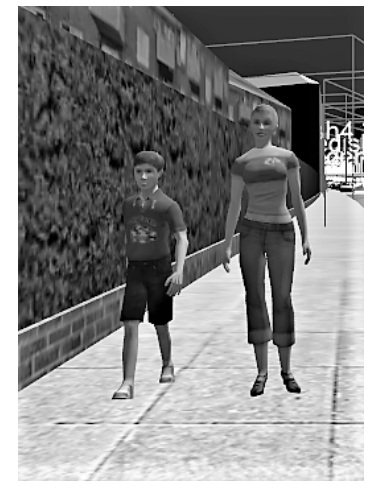

Figure 1Vizualisation of an adult and a child pedestrian.

Fifty meters before the participant reached the pedestrian, the pedestrian ran towards a ball lying at the opposite side of the street, thereby indicating to the participant that the pedestrian might cross the street. The pedestrian entered the street, but stopped after two meters without entering the path of the driver. In the visible condition, the driver could see the pedestrian the whole time (Figure 2, a). In the hidden condition, the running pedestrian disappeared behind a parked car and became partly visible only as the driver passed that car (Figure 2, b). The analysis of this one particular hazard was chosen as the only situation where the pedestrian entered the street and the driver had to respond by lowering the speed to avoid the possible accident if the pedestrian continued running. All other hazard situations did not require active response from the driver as the pedestrians were on the pavement or were standing on the side of the street. 


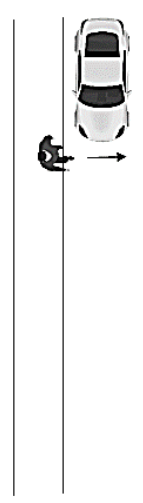

a. Visible condition

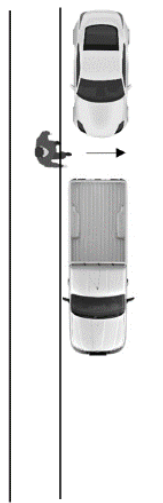

1
1
1
1
1
1
1
1
1
1
1

b. Hidden condition

Figure 2 Street-crossing situation

\subsection{Experimental procedure}

The participants read the description of the experiment, which stated that the aim was to examine drivers' everyday driving style. Then, they completed an introduction drive to get familiar with the simulator and virtual environment. Thereafter, a demographic questionnaire followed and the experiment continued with the 24 situations sub-divided into three drives, including eight situations each, completed in order determined by a Latin Square design. The participants had a short break after each drive. The whole experiment lasted about 30-45 minutes.

\subsection{Data analysis}

\subsubsection{The driving simulator data}

We examined the driving simulator data to analyse the participants' response to a pedestrian in a potential street-crossing situation. The driving simulator continuously recorded the driving speed and lateral position of the participant, but only data for the hazard window (Figure 3), from 50 meters before the pedestrian (when the pedestrian became visible for the first time) until passing the pedestrian, was included in the analysis. The participant's response to the pedestrian was detected based on the driving speed, lateral position and decrease in driving speed when approaching the pedestrian. 


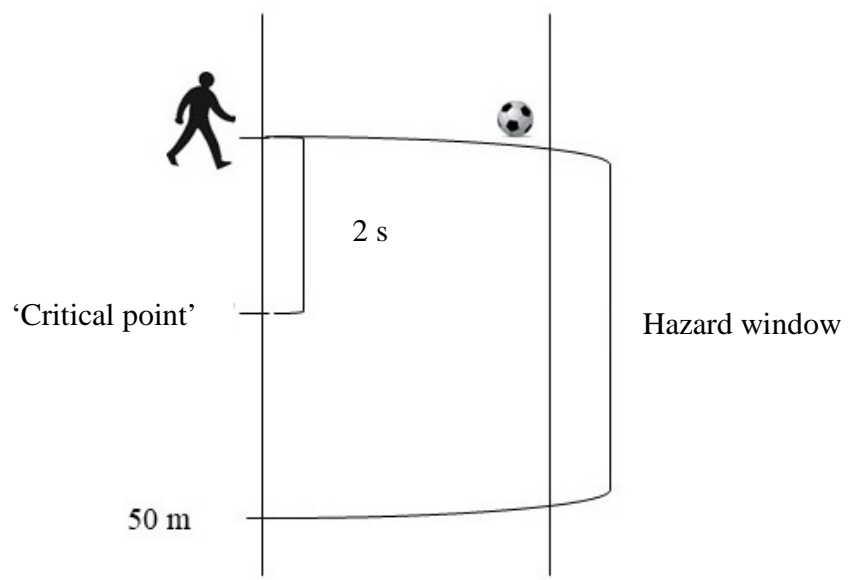

Figure 3 Schematic visualisation of the street-crossing situation

The lateral position of the vehicle is defined as the deviation in meters from the centre of the lane. The centre of the lane is the reference position (0). In this study, a larger value shows that the participant was positioned farther away from the pedestrian and thus closer to the right edge of the street. A 'critical point' of two seconds before the hazard was calculated for each participant. The 'critical point' (i.e., two seconds until passing the pedestrian) was the location after which the participant could not avoid a collision by braking if the pedestrian had continued across the street (Olson and Sivak, 1986). The driving speed at the 'critical point' was used (Olson and Sivak, 1986). We interpreted a reduction in driving speed as an indication that the participant had recognized the pedestrian as a hazard. Therefore, average speed was calculated and compared in five 10-meter intervals within the hazard window. If speed decreased for more than two standard deviations in any of the intervals, it was interpreted as slowing down. Two-way ANOVAs were employed to examine the effect of pedestrian type (child, adult) and hazard condition (visible, hidden) on driving speed at the 'critical point' and lateral position when passing the hazard. To compare whether there was a difference in slowing down to the child and adult pedestrian, we used Fisher's exact test.

\subsubsection{Eye tracker data}

Due to problems with the calibration, the eye movements of six participants were not recorded. Therefore, the eye movement analysis included 59 participants in the visible condition and 56 in the hidden condition. Dynamic areas of interest (AOI), which covered the pedestrian with additional margin, were created within the entire hazard window. The size of the AOIs was the same for adult and 
child pedestrian and their visual angle were from $2^{\circ}$ to $6^{\circ}$ including the additional margin to cover the eye trackers inaccuracy of $0.5^{\circ}$. We used two-way ANOVAs to analyse the effect of pedestrian type (child, adult) and hazard condition (visible, hidden) on the number of fixations, length of the first fixation and latency of the first fixation. These variables are commonly used to differentiate between experienced, more safe and novice, less safe drivers (e.g., Borowsky et al., 2012; Huestegge et al., 2010; Pradhan et al., 2007; Young et al., 2017).

Fixations on the speedometer within the hazard window were examined and compared among the participants who did and did not slow down in response to the child and adult pedestrian in the both conditions. Fisher's exact test was used, to compare whether there was a difference in fixation on the speedometer based on whether the child or adult pedestrian was present.

\section{Results}

\subsection{Driving speed and lateral position}

Two-way ANOVAs were conducted that examined the effect of pedestrian type (child, adult) and hazard condition (visible, hidden) on driving speed at the 'critical point' and lateral position when passing the pedestrian. Participants' speed was significantly higher at the 'critical point' with the child than with the adult pedestrian, $\mathrm{F}(1,255)=8.38, \mathrm{p}=0.004, \eta_{\mathrm{p}}{ }^{2}=0.03$. Driving speed was higher in the hidden than visible condition, $F(1,255)=8.63, p=0.004, \eta_{p}{ }^{2}=0.03$ (Figure 4). However, there was no statistically significant interaction, $\mathrm{F}(1,255)=1.66, \mathrm{p}=0.19, \eta_{\mathrm{p}}{ }^{2}=0.006$.

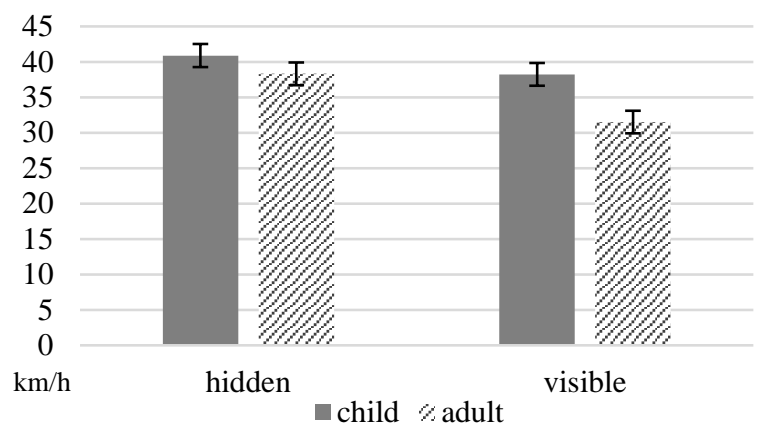

Figure 4 Driving speed at the 'critical point' 
Participants were driving significantly farther away (closer to the right edge of the street) from the child than from the adult pedestrian, $\mathrm{F}(1,255)=18.34, \mathrm{p}<0.001, \eta_{\mathrm{p}}{ }^{2}=0.07$. Additionally, participants were driving closer to the right edge in the hidden than in the visible condition, $F(1,255)=6.02, p=0.015$, $\eta_{\mathrm{p}}{ }^{2}=0.02$ (Figure 5). There was no significant interaction of pedestrian type and hazard condition, $\mathrm{F}$ $(1,255)=0.26, \mathrm{p}=0.61, \eta_{\mathrm{p}}^{2}=0.001$.

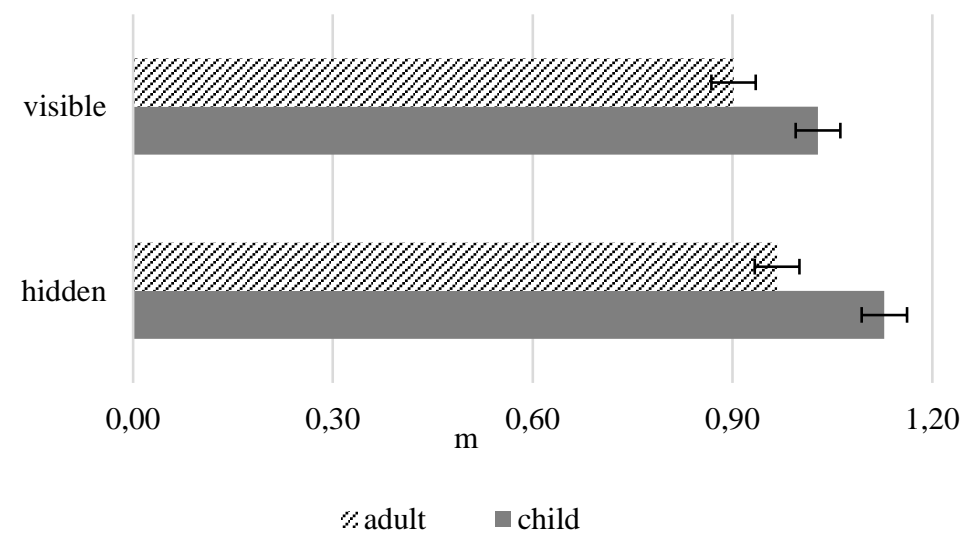

Figure 5 Lateral position when passing a pedestrian

Fisher's exact tests was performed to examine whether more participants decreased speed for the child than for the adult pedestrian. In the visible condition, significantly more participants decreased speed for the adult than for the child pedestrian ( $\mathrm{p}=0.007)$. In the hidden condition, results were similar: more drivers responded by slowing down for the adult than for the child pedestrian, however the difference was not significant $(\mathrm{p}=0.059)$ (Figure 6$)$.

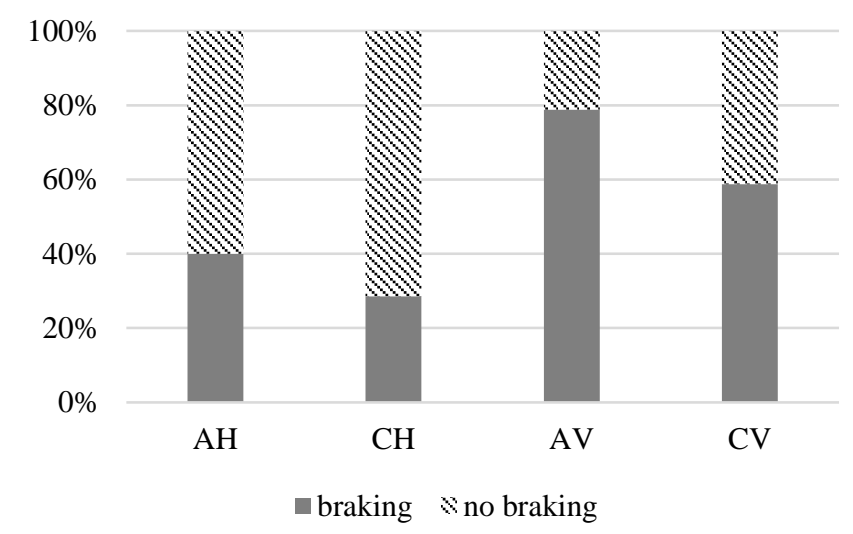

Figure 6 Number of drivers who responded to the pedestrian by slowing down (AH-adult hidden, $C H$-child hidden, AV-adult visible, $C V$-child visible) 


\subsection{Fixations on pedestrian}

All participants fixated on the pedestrian at least once. The participants fixated on the adult pedestrian more often $(\mathrm{M}=2.83, \mathrm{SD}=1.46)$ than on the child pedestrian $(\mathrm{M}=3.40, \mathrm{SD}=1.71), \mathrm{F}(1,230)=$ 7.71, $\mathrm{p}=0.006, \eta_{\mathrm{p}}{ }^{2}=0.03$. More fixations were observed in the visible condition $(\mathrm{M}=3.36, \mathrm{SD}=1.70)$ than in the hidden condition $(\mathrm{M}=2.86, \mathrm{SD}=1.49), \mathrm{F}(1,230)=6.00, \mathrm{p}=0.015, \eta_{\mathrm{p}}{ }^{2}=0.03$. The interaction effect was not significant, $F(1,230)=4.42, p=0.37, \eta_{p}{ }^{2}=0.02$.

Drivers had longer first fixations on the child pedestrian $(\mathrm{M}=1.57, \mathrm{SD}=1.37)$ than on the adult pedestrian $(\mathrm{M}=1.21, \mathrm{SD}=0.98), \mathrm{F}(1,227)=6.76, \mathrm{p}=0.01, \eta_{\mathrm{p}}{ }^{2}=0.03$. The length of the first fixation was not significantly different in the hidden and the visible condition and there was no significant interaction effect of pedestrian type and hazard condition.

A comparison of the time of the first fixation on the pedestrian did not show any significant differences for the two types of pedestrians and in the two conditions.

\subsection{Fixations on the speedometer}

Of all the participants who slowed down in the hidden condition, most of the drivers within the hazard window fixated on the speedometer, and the results are not significantly different for situations with an adult versus a child pedestrian $(\mathrm{p}=0.33$ ). In the visible condition, the difference is also insignificant ( $\mathrm{p}$ $=0.18)$ (Figure 7, a).

For the participants who did not slow down, there is no significant difference in the hidden condition with regard to the number of participants fixating on the speedometer when the adult or child pedestrian was present $(\mathrm{p}=0.16)$. In the visible condition, fewer participants fixated on the speedometer when the child was present than when the adult pedestrian was present althought the difference is not significant $(p=0.05)$ (Figure 7, b). 


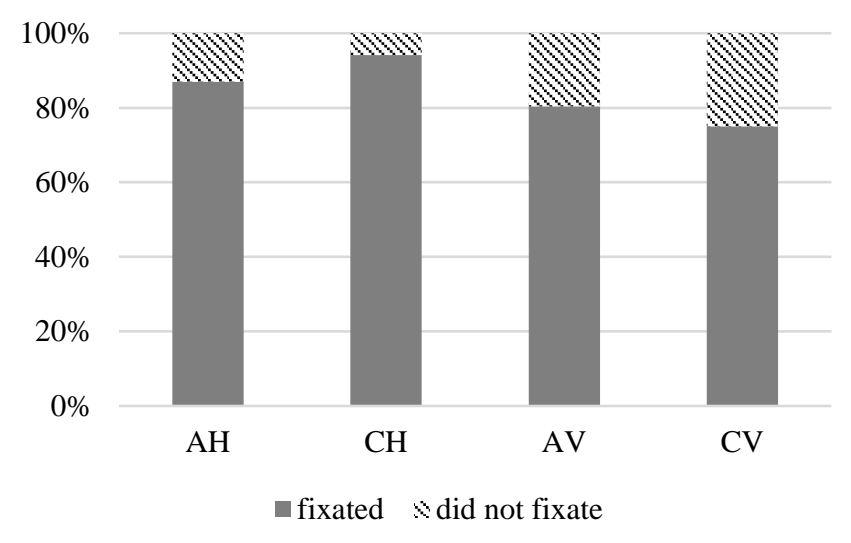

a. Drivers who slowed down (AH-adult hidden, $\mathrm{CH}$-child hidden, $A V$-adult visible, $C V$-child visible)

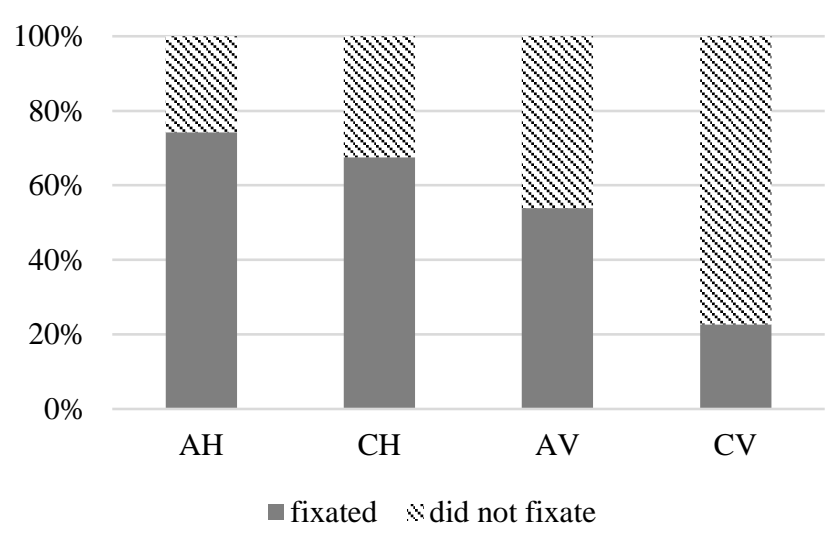

b. Drivers who did not slow down (AH-adult hidden, $\mathrm{CH}$ child hidden, $A V$-adult visible, $C V$-child visible)

Figure 7 Fixations on the speedometer

\section{Discussion}

Based on a driving simulator experiment, this study compared young drivers' responsiveness and eye movements in potential street-crossing situations with children and adults as pedestrians in visible- and hidden-hazard conditions. Our results show that young male drivers responded to a child pedestrian rather by placing the car farther away from the child than by adjusting the driving speed. Actually, fewer drivers slowed down and the driving speed was higher in events with children than with adults. Additionally, eye movement analysis showed that the time from the first fixation on the pedestrian until the driver passed was the same for both types of pedestrians. Thus, it is not probable that the reason drivers did not brake or slow down in the situation with the child was that they saw the child later than they saw the adult pedestrian. The results suggest, rather, that drivers were aware of the pedestrians but did not find it necessary to adjust their speed accordingly. Another explanation could be that the simulated adult wore grey clothing whereas the child wore bright colours providing possible confound to the size variations among the types of pedestrians.

The explanation provided by Stewart et al. (1993) for why drivers do not slow down and why they sometimes drive even faster when child pedestrians are present, because drivers tend to overestimate the distance to the child pedestrians considering them as a smaller adults (i.e., the child was considered as standing farther away than the adult), is not applicable in this study as parked cars served as a reference for the size of the pedestrian. However, it might be that the driving simulator did not provide sufficient cues indicating the varying movement pattern of child and adult pedestrian necessary to 
distinguish between the two types of pedestrians and drivers' assumptions, so that children were perceived as small adults. Additionally, the lack of disparity information in the simulator and a cue to flatness provided by the frame of the simulator screen might have had an effect on depth and distance perception of the visuals in the scenarios (Andersen, 2011). However, in that instance one expected the same reactions to both types of pedestrians, which was not the case. Another explanation could be that drivers are not slowing down for the child pedestrian as they think that children might understand this as an invitation to cross the street and in case of children - more than in case of adults - they want to avoid any unclear signals.

An alternative reason for the higher speed around child pedestrians could be that drivers did not estimate their actual driving speed correctly. Our findings show that fewer drivers that did not respond to the pedestrian by decreasing speed, fixated on the speedometer when the child pedestrian was present, suggesting that they did not consider decreasing the driving speed irrespective of the actual driving speed. Harré (2003) found that drivers evaluated their speed as lower than their actual driving speed when passing pedestrians, especially child pedestrians, suggesting that drivers probably consider that it is necessary to decrease the speed near children but lack an accurate speed perception. However, another reason could be that young drivers are not aware of children's limited ability to cope with traffic and are not aware of the risks associated with the child pedestrian. That could be further explored in qualitative studies.

Another relevant suggestion for further studies could be setting up a video camera filming the driver's feet observing whether the participant is keeping a foot on the brake pedal ready to brake when approaching the pedestrian. This measure could provide an indication of driver's hazard awareness. If the driver gets ready to brake but decides not to, the issue could be a lack of correct estimation of required braking time associated with the driver's inexperience.

Our study is based on a sample of young male drivers. It thus remains unknown if the inadequate speed adjustment in relation to child pedestrians is a specific problem of this target group or can also be found in other driver populations. However, young male drivers' lower hazard perception skills (e.g. Borowsky et al., 2010) and higher risk acceptance (e.g. Clarke et al., 2005; Williams, 2003) suggest 
that the problem is more pronounced in this group than in other driver segments. Still, further studies are required to examine whether drivers in all age, gender and experience groups perform similarly in potential street-crossing situations with child and adult pedestrians, helping to address this problem to the relevant target groups and adjust preventive methods respectively. To examine how the results of this study translates to the real world, naturalistic on-road experiment are suggested for the further studies.

In conclusion, although child pedestrian behaviour brings higher risks into road safety due to immaturity, lack of experience and low motoric skills, young male drivers are not considering this by speed reduction in potential street-crossing situations. The results indicate a need for raising the awareness on the necessity of speed adjustment in potential street-crossing situations, especially those involving children, and to find solutions on how to mitigate these accident occurrences, which could be examined in qualitative research. A better understanding of how drivers respond to the different types of pedestrians and why could also serve as a valuable input for the development of pedestrian detection and emergency braking systems and for the improvements of driver education.

\section{Acknowledgement}

Financial support from TrygFonden is greatly appreciated. The authors would like to express gratitude to Quentin Tresontani for his contribution to data collection and the eye-tracker data analysis.

\section{References}

Andersen, G.J., 2011. Sensory and Perceptual Factors in the Design of Driving Simulation Displays, in: Fisher, D.L., Rizzo, M., Caird, J.K., Lee, J.D. (Eds.), Driving Simulation for Engineers, Medicine, and Psychology. CRC Press, Boca Raton.

Bennet, S.A., Yiannakoulias, N., 2015. Motor-vehicle collisions involving child pedestrians at intersection and mid-block locations. Accid. Anal. Prev. 78, 94-103. doi:10.1016/j.aap.2015.03.001

Borowsky, A., Oron-Gilad, T., Meir, A., Parmet, Y., 2012. Drivers’ perception of vulnerable road users: a hazard perception approach. Accid. Anal. Prev. 44 1, 160-6. doi:10.1016/j.aap.2010.11.029

Borowsky, A., Shinar, D., Oron-Gilad, T., 2007. Age, skill, and hazard perception in driving. Accid. Anal. Prev. 424 , 1240-9. doi:10.1016/j.aap.2010.02.001

Briem, V., Bengtsson, H., 2000. Cognition and character traits as determinants of young children's behaviour in traf situations. Int. J. Behav. Dev. 244 , 492-505. 
Chapman, P.R., Underwood, G., 1998. Visual search of driving situations: Danger and experience. Perception 278 , 951-964.

Clarke, D.D., Ward, P., Truman, W., 2005. Voluntary risk taking and skill deficits in young driver accidents in the UK. Accid. Anal. Prev. 37, 523-529. doi:10.1016/j.aap.2005.01.007

Cloutier, M.-S., Lachapelle, U., d’Amours-Ouellet, A.-A., Bergeron, J., Lord, S., Torres, J., 2017. “Outta my way!” Individual and environmental correlates of interactions between pedestrians and vehicles during street crossings. Accid. Anal. Prev. 104 , 36-45.

doi:10.1016/j.aap.2017.04.015

Coelingh, E., Eidehall, A., Bengtsson, M., 2010. Collision warning with full auto brake and pedestrian detection - A practical example of automatic emergency braking, in: IEEE Conference on Intelligent Transportation Systems, Proceedings, ITSC. pp. 155-160. doi:10.1109/ITSC.2010.5625077

Connelly, M.L., Conalen, H.M., Parsonson, B.S., Isler, R.B., 1998. Child Pedestrians’ Crossing Gap Tresholds. Accid. Anal. Prev 304 , 443-453.

Deery, H.A., 1999. Hazard and Risk Perception among Young Novice Drivers. J. Safety Res. 304 , 225-236. doi:10.1016/S0022-4375(99)00018-3

Hamed, M.M., 2001. Analysis of pedestrians' behavior at pedestrian crossings. Saf. Sci. 38, 63-82.

Harré, N., 2003. Discrepancy between actual and estimated speeds of drivers in the presence of child pedestrians. Inj. Prev. 9, 38-41.

Huestegge, L., Skottke, E.-M., Anders, S., Müsseler, J., Debus, G., 2010. The development of hazard perception: Dissociation of visual orientation and hazard processing. Transp. Res. Part F Traffic Psychol. Behav. 13 1 , 1-8. doi:10.1016/j.trf.2009.09.005

Jager, M., Nyffeler, T., Muri, R., Mosimann, U.P., Nef, T., Jaager, M., Nyffeler, T., Muri, R., Mosimann, U.P., Nef, T., Jager, M., Nyffeler, T., Muri, R., Mosimann, U.P., Nef, T., 2015. Adapting a Driving Simulator to Study Pedestrians' Street-Crossing Decisions: A Feasibility Study. Assist. Technol. 27, 1-8. doi:10.1080/10400435.2014.929193

Konstantopoulos, P., Chapman, P., Crundall, D., 2010. Driver's visual attention as a function of driving experience and visibility. Using a driving simulator to explore drivers' eye movements in day, night and rain driving. Accid. Anal. Prev. 423 , 827-34. doi:10.1016/j.aap.2009.09.022

Lubbe, N., Davidsson, J., 2015. Drivers' comfort boundaries in pedestrian crossings: A study in driver braking characteristics as a function of pedestrian walking speed. Saf. Sci. 75, 100-106. doi:10.1016/j.ssci.2015.01.019

Meyer, S., Sagberg, F., Torquato, R., 2014. Traffic hazard perception among children. Transp. Res. Part F Traffic Psychol. Behav. 26 PA , 190-198. doi:10.1016/j.trf.2014.07.007

National Center for Statistics and Analysis, 2017. Traffic Safety Facts 2013, NHTSA. doi::obi:DOT HS 812148

OECD/IFT, 2015. Road Safety Annual Report 2015. Paris.

Olson, P.L., Sivak, M., 1986. Perception-Response Time to Unexpected Roadway Hazards. Hum. Factors $281,91-96$.

Pitcairn, T.K., Edlmann, T., 2000. Individual differences in road crossing ability in young children and adults. Br. J. Psychol. 91, 391-410. doi:10.1348/000712600161899

Poschadel, S., 2006. Prototypische Kinderunfälle im innerstädtischen Straßenverkehr Von Unfallanalysen über Präventionsmöglichkeiten zur Entwicklung eines Unfallmodells Inhaltsverzeichnis. (Doctoral thesis, Ruhr-Universität Bochum, Germany). Retrieved from: 
http://www-brs.ub.ruhr-uni-bochum.de/netahtml/HSS/Diss/PoschadelSebastian/diss.pdf

Pradhan, A., Pollatsek, A., Fisher, D.L., 2007. Comparison of trained and untrained novice drivers' gaze behaviour in risky and non-risky scenarios, in: Proceedings of the Fourth International Driving Symposium in Human Factors and Driver Assesment, Training and Vehicle Design. pp. 328-334.

Rosén, E., Källhammer, J.-E., Eriksson, D., Nentwich, M., Fredriksson, R., Smith, K., 2010. Pedestrian injury mitigation by autonomous braking. Accid. Anal. Prev. 42, 1949-1957. doi:10.1016/j.aap.2010.05.018

Rothman, L.M., 2014. Child Pedestrian-Motor Vehicle Collisions and Walking to School in the City of Toronto: The Role of the Built Environment. University of Toronto.

Schieber, R.E., Vegega, M.E., 2002. Reducing childhood pedestrian injuries. Inj. Prev. 8, 3-8.

Schwebel, D.C., Davis, A.L., O ’neal, E.E., 2012. Child Pedestrian Injury: A Review of Behavioral Risks and Preventive Strategies. Am. J. Lifestyle Med. 292-302. doi:10.1177/0885066611404876

Stewart, D., Cudworth, C.J., Lishman, J.R., 1993. Misperception of time-to-collision by drivers in pedestrian accidents. Perception 22, 1227-1244.

Thompson, S.J., Fraser, E.J., Howarth, C.I., 1985. Driver behaviour in the presence of child and adult pedestrians. Ergonomics 2810 , 1469-1274.

Tobii Technology, 2012. Determining the Tobii I-VT Fixation Filter's Default Values, Tobii WhitePaper.

Underwood, G., Chapman, P., Bowden, K., Crundall, D., 2002. Visual search while driving: skill and awareness during inspection of the scene. Transp. Res. Part F Traffic Psychol. Behav. 52 , 8797. doi:10.1016/S1369-8478(02)00008-6

Williams, A.F., 2003. Teenage drivers: patterns of risk. J. Safety Res. 34, 5-15.

Young, A.H., Crundall, D., Chapman, P., 2017. Commentary driver training: Effects of commentary exposure, practice and production on hazard perception and eye movements. Accid. Anal. Prev. 101, 1-10. doi:10.1016/j.aap.2017.01.007

Zito, G.A., Cazzoli, D., Scheffler, L., Jäger, M., Müri, R.M., Mosimann, U.P., Nyffeler, T., Mast, F.W., Nef, T., 2015. Street crossing behavior in younger and older pedestrians: an eye-and headtracking study. BMG Geriatr. 15 176 . doi:10.1186/s12877-015-0175-0 